\title{
Parental Attitudes toward Ethical and Social Issues Surrounding the Expansion of Newborn Screening Using New Technologies
}

\author{
L.E. Hasegawa ${ }^{a} \quad$ K.A. Fergus ${ }^{a} \quad$ N. Ojeda ${ }^{b}$ S.M. Au \\ ${ }^{a}$ Hawaii Genetics Program, Children with Special Needs Branch, Hawaii Department of Health, Honolulu, Hawaii, \\ and ${ }^{b}$ Genetic Disease Screening Program, California Department of Public Health, Richmond, Calif., USA
}

\section{Key Words}

Cultural differences · Ethical issues • Focus group • Informed consent $\cdot$ Metabolic disorders $\cdot$ Newborn screening $\cdot$ Qualitative analysis $\cdot$ Social issues

\begin{abstract}
Aims: This study assessed parent knowledge of newborn screening (NBS) and parent attitudes toward NBS for untreatable conditions, NBS for late-onset disorders and informed consent in NBS. Methods: Seventeen qualitative focus groups were held in Alaska, California, Hawaii, and Washington with mothers of children 10 years old or younger. Results: Most participants did not recall receiving information about NBS, and all wanted this information prenatally. In addition, most felt that the current system of 'informed dissent' was adequate, provided they were told about NBS prior to delivery. All women supported NBS for conditions that occur in infancy without a proven treatment. However, they disagreed about NBS for disorders that manifest in late childhood or adulthood. Conclusions: The results show a general consensus among the focus group participants about issues that cause dissent among public health and health care professionals. Parent attitudes differ from those of many professional communities with regard to timing of NBS education, informed consent, NBS for disorders that lack
\end{abstract}

an effective treatment, and predictive testing of children for late-onset disorders. The results highlight the need to further research parent opinions about expanded NBS using new technologies and to include parents in the development of NBS policies.

Copyright $\odot 2010$ S. Karger AG, Basel

\section{Introduction}

Newborn screening (NBS) is a public health activity that identifies infants with certain genetic or metabolic conditions. Early diagnosis of these conditions is critical because timely intervention can lead to a significant reduction in morbidity, mortality and associated disabilities. Since its implementation in the 1960's, NBS has been a model public health program. However, advances in genomics and medical technology have rapidly increased our ability to screen for asymptomatic disease. This threatens to outpace our understanding of the conditions for which we can screen and presents ethical challenges for both healthcare professionals and families.

When NBS was first established, Wilson and Junger [1] developed 10 principles that have largely guided the NBS process over the past 40 years (table 1). These criteria focus heavily on the diagnosis and management of screen

\section{KARGER}

Fax +4161306 1234

E-Mail karger@karger.ch

www.karger.com
(C) 2010 S. Karger AG, Basel

$1662-4246 / 11 / 0145-0298 \$ 38.00 / 0$

Accessible online at:

www.karger.com/phg
Lianne E. Hasegawa, MS

Hawaii Department of Health

741 Sunset Avenue

Honolulu, HI 96816 (USA)

Tel. +1 808733 9039, Fax +1 808733 9068, E-Mail lianne@ hawaiigenetics.org 
Table 1. Principles of early disease detection [1]

1. The condition should be an important health problem.

2. There should be an accepted treatment for patients with recognized disease.

3. Facilities for diagnosis and treatment should be available.

4. There should be a recognizable latent or early symptomatic stage.

5 . There should be a suitable test or examination.

6. The test should be acceptable to the population.

7. The natural history of the condition, including development from latent to declared disease, should be adequately understood.

8. There should be an agreed policy on whom to treat as patients.

9. The cost of case-finding should be economically balanced in relation to possible expenditure on medical care.

10. Case-finding should be a continuing process and not a 'once and for all' project.

positive individuals and require that a screened disorder has an effective treatment and a well-understood natural history. The expansion of NBS by tandem mass spectrometry (MS/MS) in the early 2000s directly challenged Wilson and Junger's principles by allowing for the detection of conditions so rare that information about natural history and effective treatments is still lacking [2]. In fact, a comprehensive review of NBS via MS/MS concluded that only 2 of over 30 disorders detected by MS/MS had sufficient evidence about incidence and outcomes to support inclusion in NBS panels [3]. Yet, proponents of expanded NBS by MS/MS argue that Wilson and Junger's criteria are too narrow and fail to incorporate benefits other than treatment of disease [4].

The application of MS/MS to NBS has raised a second ethical dilemma: that of the mandatory nature of NBS. Currently, all U.S. states except Maryland and Wyoming mandate NBS unless parents object [5]. Most healthcare professionals feel that mandatory NBS is justified if an effective treatment is available for the screened disorders $[6,7]$. However, when the benefit of screening is less clear, such as in expanded NBS for untreatable conditions, mandatory NBS becomes controversial. Some professionals contend that mandated NBS should only include disorders that fulfill Wilson and Junger's screening principles [8], while others argue that informed consent is difficult to implement and could decrease the number of newborns offered screening [9]. The tension between these views will only increase as additional diseases are considered for inclusion on expanded NBS panels.

Indeed, as our technology continues to improve, we will likely gain the capacity to screen for hundreds of new diseases that will further challenge Wilson and Junger's principles. For instance, DNA microarrays, an increas- ingly common DNA-based technology, could potentially permit NBS for adult-onset conditions such as cardiovascular disease [10]. While most professional organizations are against predictive testing of children for late-onset conditions [11-16], parents from a study in Chicago believe that they, and not professional groups, should make the final decision about predictive testing for their children $[17,18]$.

The debate surrounding expanded NBS using new technologies is complex and has primarily centered on the opinions of professionals. Only a handful of studies have assessed the views of parents [17-21], and none have examined the issue of NBS for adult-onset conditions. Since parents will be directly affected by NBS policies developed by professional groups, it is important that their attitudes are researched and considered, especially in light of Campbell and Ross' findings that parental opinions about NBS differed significantly from those of professionals $[17,18]$. As such, the current study assessed parents' attitudes toward 3 issues associated with expanded NBS using new technologies: (1) NBS for disorders without treatments, (2) NBS for disorders that manifest in childhood and adulthood and (3) informed consent in expanded NBS.

\section{Methods}

All materials and methods were approved by the Hawaii Department of Health Institutional Review Board.

Design

Seventeen 2-hour, semi-structured focus groups were conducted in Alaska, California, Hawaii, and Washington between 2003 and 2004. Introductory questions were first asked about 
Table 2. Key characteristics of focus groups

\begin{tabular}{llll}
\hline State & $\begin{array}{l}\text { Number and type } \\
\text { of focus group }\end{array}$ & $\begin{array}{l}\text { Number of participants } \\
\text { per group }\end{array}$ & $\begin{array}{l}\text { Total number of } \\
\text { participants }\end{array}$ \\
\hline Alaska & 3 general public & $9,4,4$ & 17 \\
\hline California & 2 English-speaking & 7,5 & 26 \\
\hline 2 Spanish-speaking & 7,7 & 48 \\
\hline Wawaii & 3 urban & $9,8,8$ & 23 \\
\hline
\end{tabular}

Table 3. Key characteristics of focus group participants $(n=114)$

\begin{tabular}{lc}
\hline Category & $\mathrm{n}(\%)$ \\
\hline Age & \\
$\leq 20$ & $4(3.5)$ \\
$21-30$ & $34(29.8)$ \\
$31-40$ & $59(51.8)$ \\
$41-50$ & $13(11.4)$ \\
Blank & $4(3.5)$ \\
Education level & \\
Did not graduate from high school & $11(9.6)$ \\
High school graduate & $30(26.3)$ \\
Some college/college graduate & $69(60.5)$ \\
Blank & $4(3.5)$ \\
Ethnic background & \\
African American/Black & $24(21.1)$ \\
Caucasian/White & $14(12.3)$ \\
Chinese & $4(3.5)$ \\
Filipino & $5(4.4)$ \\
Hawaiian or part-Hawaiian & $23(20.2)$ \\
Hispanic/Latino & $7(6.1)$ \\
Japanese & $27(23.7)$ \\
Native American & $4(3.5)$ \\
Blank & $6(5.3)$ \\
Age of youngest child & \\
$<1$ & $19(16.7)$ \\
$1-5$ & $71(62.3)$ \\
6-10 & $22(19.3)$ \\
Blank & $2(1.8)$ \\
\hline
\end{tabular}

knowledge and recall of NBS. Questions then centered on attitudes toward: NBS for disorders presenting in infancy with little or no known effective treatments; NBS for disorders presenting in childhood or adulthood; and informed consent for NBS. Glutaric acidemia type 2 , a condition for which treatment has not been effective in many newborns, was given as an example of an untreatable disorder presenting in infancy. Duchenne muscular dystrophy (DMD), a muscle disease in which symptoms occur between 3 and 10 years of age, was used as an example of predictive screening for a disorder that presents in childhood. ApoE susceptibility testing for Alzheimer disease (AD) demonstrated predisposition testing for disorders presenting in adulthood. A range of questions was asked for each condition, including whether or not participants would screen their newborn, advantages and disadvantages to screening, who they would disclose results to, and how results might affect the parent-child relationship. All sessions were audiotaped.

\section{Participants}

Participants were mothers whose youngest child was no older than 10 years. All had healthy children with normal NBS results. To ensure representation from diverse backgrounds, 7 focus groups included only women from traditionally underrepresented populations, including non-English speaking Hispanics, African-Americans, and Asians and Pacific Islanders from rural communities (table 2).

Participants were recruited through community organizations, state health programs, healthcare centers, and special interest groups. A leader within each organization was initially contacted; flyers detailing the study, focus group dates, and contact information for the study coordinator were electronically mailed. The organization leader distributed the flyer and interested women contacted the study coordinator. The study coordinator assigned women to focus groups based on their schedules and the demographic criteria of the groups. A 25 USD gift card and meal were provided, and written consent was obtained prior to participation.

A total of 114 women, ranging in age from 18-49 years, participated in the focus groups. The majority were: college educated (60.5\%); Japanese-American or African-American (23.7\% and $21.1 \%$, respectively); between the ages of $31-40$ (51.8\%); and had a child between $1-5$ years (62.3\%) (table 3 ).

\section{Facilitators}

The focus groups were moderated by 3 researchers. All received formal facilitation training prior to facilitating the groups. The Spanish-language groups were conducted in Spanish. An ad- 
Table 4. Themes noted from responses of focus group participants

\begin{tabular}{|c|c|c|}
\hline Themes & $\begin{array}{l}\text { Groups }(\mathrm{n}=17) \\
\mathrm{n}(\%)\end{array}$ & $\begin{array}{l}\text { Participants }(\mathrm{n}=114) \\
\mathrm{n}(\%)\end{array}$ \\
\hline Limited recall of NBS & $16(94.1)$ & $75(65.8)$ \\
\hline \multicolumn{3}{|l|}{ Prenatal dissemination of NBS information } \\
\hline Impractical to be told after delivery & $7(100.0)$ & $85(74.6)$ \\
\hline Third trimester is best time to learn about NBS & $10(58.8)$ & $82(71.9)$ \\
\hline Obstetrician should provide verbal information & $7(41.1)$ & $26(22.8)$ \\
\hline \multicolumn{3}{|l|}{ NBS for untreatable conditions in infancy is supported } \\
\hline Would help to prepare caregivers & $17(100.0)$ & $39(34.2)$ \\
\hline Eliminate questions and doubts & $6(35.3)$ & $15(13.2)$ \\
\hline Native Hawaiians emphasized family & $4(23.5)$ & \\
\hline \multicolumn{3}{|l|}{ NBS for late-onset disorders is controversial } \\
\hline Would help to prepare caregivers & $11(64.7)$ & $42(36.8)$ \\
\hline Parental right to information & $3(17.6)$ & $10(8.8)$ \\
\hline Knowledge would be burdensome & $13(76.5)$ & $54(47.4)$ \\
\hline Risk for vulnerable child syndrome & $3(17.6)$ & $14(12.3)$ \\
\hline \multicolumn{3}{|l|}{ Informed consent for NBS } \\
\hline Unnecessary if education provided prenatally & $17(100.0)$ & $111(97.4)$ \\
\hline May decrease chance that all babies are screened & $17(100.0)$ & $84(73.7)$ \\
\hline $\begin{array}{l}\text { Spanish-speaking women worried it would decrease screening } \\
\text { due to language barrier }\end{array}$ & $2(11.8)$ & $14(12.3)$ \\
\hline Do not mandate NBS for late-onset conditions & $17(100.0)$ & $87(76.3)$ \\
\hline
\end{tabular}

ditional staff member recorded the discussion and documented nonverbal events.

At the start of the focus group, the facilitator presented a 10 minute scripted overview about NBS. This brief educational component ensured that all participants had the same baseline knowledge of NBS. The facilitator also provided limited clarification about NBS and other health-related facts as needed throughout the session. Key questions were predetermined. However, the facilitator occasionally asked unscripted questions to gain more insight into particular responses. These most often related to participants' cultures and personal experiences.

Analysis

Participant responses were qualitatively examined using focus group transcripts. The transcripts from the Spanish groups were translated into English by a professional translating service and reviewed by a bilingual health educator. Responses were analyzed using the long-table analysis method [22]. Transcripts were first read to consider potential themes. Each theme was discussed by the facilitators, who conferred on possible meanings and perspectives. A comparative analysis spreadsheet containing headings based on the identified themes was then generated. The transcripts were again reviewed, and quotes related to each theme were categorized on the spreadsheet. The number of focus groups in which a particular theme emerged was tallied, along with the number of participants who spoke to each theme. Because not every participant responded verbally to all topics, individual support for the themes is likely underestimated. Major themes, defined as topics independently raised and discussed in at least 3 focus groups, were crossed referenced with demographic infor-

Parental Attitudes toward Newborn

Screening: A Focus Group Study mation and field notes. Two researchers reviewed the transcripts and coded themes to ensure uniformity. Data, analyses and conclusions were also reviewed by an evaluation specialist.

\section{Results}

Five major themes were noted within the participant responses. Each theme represented a topic that was emphasized in at least 3 focus groups (table 4 ).

\section{Limited Recall of Newborn Screening}

Most participants could not recall NBS. Although some readily remembered concrete images associated with the procedure, such as the bandage on their baby's heel or the heelstick process, many did not remember being told about NBS or its implications. Only 21 of 114 participants (18.4\%) could provide specific facts about NBS, and most were healthcare professionals (midwives, medical assistants or nurses).

\section{Prenatal Dissemination of Newborn Screening Information}

Participants from all 17 focus groups expressed dissatisfaction with the current method of providing NBS 
information immediately before or after the delivery of a child. Many described this as impractical because they were too exhausted to understand the details of the test. Instead, mothers from each focus group independently suggested that education be provided during the prenatal period. The women argued that having NBS information prenatally would give them time to better comprehend the implications of NBS.

While there was some variation, most thought receiving NBS education during the third trimester was ideal. The participants felt their babies became more 'real' to them during the third trimester, and they would therefore be more likely to pay attention to information about newborn procedures.

Participants from 7 focus groups (2 rural Hawaii groups, 3 Alaska groups, and 2 African-American groups) independently identified the obstetrician as the most practical person to provide NBS education, and at least one mother from each group wanted a verbal explanation about NBS. These women reasoned that simply distributing a NBS brochure would be unsuccessful because many parents would not read it. A mother from an AfricanAmerican focus group explained: 'If someone gave me [a NBS brochure], it would become junk mail. And what do you do with junk mail? You trash it. So it's important for someone to sit me down and explain this piece of paper.'

\section{Newborn Screening for Untreatable Disorders That \\ Present in Infancy Is Supported}

All participants supported NBS for untreatable conditions presenting in infancy. Many women wanted this information to prepare themselves, their families and medical professionals to cope with potential complications of the disorder. Others stated that an early diagnosis would eliminate questions and doubts about their child's illness. They explained it would be harder not knowing what was wrong with their baby than it would be to deal with positive NBS results identifying an untreatable condition.

When compared to mothers of other ethnic backgrounds, Native Hawaiian participants consistently emphasized the importance of sharing NBS information with family members. All said they would turn to their families for help and support if their newborn was diagnosed with an untreatable condition. They described the family unit as vital during times of emotional strain and saw it as a significant source of strength. A Native Hawaiian participant from a rural Hawaii focus group clarified this point: 'Well, normally, here in Hawaii ... family is very important. It's the backbone of everything here in the islands. And your family will be behind you $100 \%$, anything that you need ... all your 'ohana [Hawaiian word for 'family'] would be there if something happened.'

After realizing that positive NBS results could have implications on the reproductive risks of other family members, some Native Hawaiians additionally felt an obligation to have their newborns screened so that results could be disclosed to their families.

\section{Newborn Screening for Late-Onset Disorders Is Controversial}

Attitudes toward NBS for DMD and AD were mixed. Participants from 12 focus groups were evenly split over NBS for these disorders, participants from 2 groups (rural Hawaii group and Washington mixed ethnicity group) unanimously supported this type of screening, and participants from 3 groups (urban Hawaii group, rural Hawaii group and Washington mixed ethnicity group) were unanimously against NBS for conditions that manifest in childhood or adulthood. A review of the transcripts from the 5 focus groups which unanimously supported or opposed NBS for late-onset conditions revealed that each of the participants independently agreed or disagreed with NBS for DMD and AD versus being persuaded by a dominant voice.

In total, 56 participants (49.1\%) indicated they would screen their newborns for $\mathrm{DMD}$ and $\mathrm{AD}$, while 58 participants (50.9\%) would not want their newborn screened if a preventive treatment was unavailable. The age of onset of the condition did not influence whether a participant supported or opposed NBS for late-onset disorders. Mothers who were interested in late-onset NBS wanted NBS results for both DMD and AD, and mothers who did not want their newborn screened said they were against NBS for both conditions.

The 56 participants who supported NBS for late-onset conditions believed it would be helpful to know any information about their child, including predictive testing results. Using phrases like 'knowledge is power', these mothers argued that the information would help them plan for the future, learn about the disorder, advocate for a treatment, and keep abreast of current research.

In 3 focus groups (urban Hawaii group, AfricanAmerican group and Washington mixed ethnicity group), the discussion led to a debate about parental rights. At least 2 participants from each group believed that a child's health information belongs to the parents. They reasoned that parents have a right to know the diseases their children will develop, including late-onset conditions like AD. 
The most common concern among the 58 mothers who did not want their newborn screened was the potential for the knowledge to become psychologically taxing. These participants expressed discomfort over predictive NBS and believed that coping with the results would be difficult. They described the knowledge as 'burdensome' and felt it would dramatically increase parental anxiety.

Participants from 3 focus groups (urban Hawaii group, Washington mixed ethnicity group, and English-speaking California group) additionally worried that some parents might treat a healthy child as disabled if they knew he/she would develop DMD or AD in the future. The following quote from a mother in an urban Hawaii group reflects the discussions: 'If the child is normal and then you know that at a certain age they're going to get [a condition] ... it might handicap them. The parent tries to protect the child, but ... they [end up] doing everything for the child ... and then the child has this mentality that ... I'm going to get this disease and I don't have to do anything ... So it's dangerous in that sense.'

Other participants discussed the more extreme possibility of parents physically harming their child if they knew that he/she would develop a debilitating condition later in life.

\section{Informed Consent for Newborn Screening}

All participants except 3 mothers in an English-speaking California group supported mandatory NBS for conditions presenting in infancy, with the provision that NBS education is provided prenatally. Most participants were more troubled over the lack of NBS education than by the lack of consent. Some mothers worried that informed consent might cause parents to refuse NBS due to lack of knowledge, while others were concerned that informed consent would decrease equal access to NBS.

Spanish-speaking participants, in particular, strongly supported mandatory NBS for conditions presenting in infancy. They explained that members of the Spanishspeaking community are often unaware of the benefits of medical intervention and public health activities and might refuse NBS due to lack of information. Other Spanish-speaking mothers worried that the language barrier would deter parents from NBS if an informed consent system were instituted. One Spanish-speaking participant summarized this view: 'Sometimes there are people that don't know even a bit of English [and] in the hospitals, people know absolutely no Spanish ... They speak half Spanish and half English and they don't understand each other ... And as they're babies, they're going to die because their parents couldn't understand?'

Parental Attitudes toward Newborn Screening: A Focus Group Study
However, due to the wide gaps in beliefs over NBS for late-onset conditions, most participants believed that NBS for conditions that occur in late childhood or adulthood should not be mandated and that parents should be able to choose whether or not to screen their child.

\section{Discussion}

\section{Newborn Screening Education}

Our results show that parents lack information about routine NBS and believe that NBS education should be provided during the third trimester of pregnancy by obstetricians. This supports findings from previous studies conducted in the U.S., U.K. and Netherlands [17-20, 23].

Like the mothers in our study, several professional groups have advocated for incorporating NBS education into prenatal care and for obstetricians to counsel parents about NBS [24-26]. However, when surveyed about NBS, less than $33 \%$ of obstetricians reported consistently discussing NBS with families $[27,28]$. Lack of time and knowledge were most often cited as reasons for not explaining NBS, but many also believed that NBS was a pediatric issue and therefore outside of the scope of prenatal care [27-29]. This confusion about the obstetrician's role in NBS is amplified by the failure of most U.S. states to define the responsibilities of healthcare providers in NBS education [30].

To engage obstetricians within the NBS system, the public health community must first clearly delineate their responsibilities in counseling families about NBS. Comprehensive educational resources must also be made available to help obstetricians inform parents about NBS. Some suggest that a U.S. policy for NBS education and materials content would improve the quality of NBS resources and allow healthcare professionals to more easily provide NBS education [31]. Ensuring prenatal NBS education, thus, requires that public health and healthcare professionals work collaboratively to develop clear policies about NBS educational resources and define the roles of clinical providers in NBS education.

\section{Newborn Screening for Untreatable Disorders That}

Present in Infancy

Women in all 17 focus groups supported NBS for untreatable conditions presenting in infancy. This directly contradicts Wilson and Junger's second screening principle which states that a screened disorder must be associated with an available treatment. The women's views also challenge opinions held by many professionals who be-

Public Health Genomics 2011;14:298-306 
lieve a disorder should not be included in NBS if the benefit of medical treatment is uncertain [32-34].

Bailey contends that medical treatment is only one benefit of NBS [35] and argues that NBS should be justified not on the availability of treatment, but on whether a benefit is obtained [36]. This view is strongly supported by participants who felt that the nonmedical benefits of NBS outweighed the medical 'harm' of a lack of treatment. They consistently emphasized the importance of emotional preparation, support and research and alluded to the avoidance of the 'diagnostic odyssey' often experienced by families of severely ill children [37].

Native Hawaiian participants particularly wanted this information to share with their 'ohana, or family. The concept of 'ohana is an important value within the Native Hawaiian culture [38], and the 'ohana's well-being often takes precedence over the individual needs of family members $[39,40]$. This cultural sense of responsibility, or kuleana, for the 'ohana explains the emphasis Native Hawaiian mothers placed on obtaining and sharing NBS information. Only Native Hawaiian participants justified NBS by citing the benefit of communicating recurrence risks to family members, and this reasoning is likely rooted in their cultural ideas of kuleana and 'ohana.

Participants' acceptance of NBS for untreatable conditions presenting in infancy is significant, especially given the diversity of the women in our study. This unanimous support suggests that Wilson and Junger's screening principles should be updated to include a broader concept of benefit beyond that of medical treatments, and provides evidence for those challenging the tenet that NBS should only be considered if a treatment is available.

\section{Newborn Screening for Late-Onset Disorders}

Participants' reactions were mixed regarding NBS for disorders that manifest in childhood or adulthood. Some wanted NBS results for preparation or to advocate for a treatment, while others viewed the information as burdensome.

Although several professionals support predictive testing of minors and the authority of parents to test children for late-onset conditions [41-44], this support is given within the context of a family history that puts the newborn at high risk for a particular condition. Most professionals will not consider population-based predictive screening in newborns, and many genetics societies have cautioned against predictive testing of minors for conditions lacking treatment [11-16]. They cite the loss of the child's future autonomy (since parents, and not the child, make the decision to be tested), the breach of confidenti- ality (since parents will know the child's results) and the possibility of psychosocial harm as arguments against predictive testing in children [45]. For these reasons, professional groups recommend postponing predictive testing until a child reaches the age of majority.

Nevertheless, approximately $50 \%$ of our participants were interested in the NBS information. While this difference in parent and professional attitudes could represent different levels of knowledge, the conflicting views may also signify different values [17]. If this is the case, involving the public in the development of genetic and NBS policies is necessary to ensure that the values held by the lay population are represented and considered by professional societies [18].

Because NBS for late-onset conditions was not universally supported, predictive testing should not be included in a mandatory, population-based screening program. Instead, if it is conducted, it should be offered with proper informed consent within a program designed to maximize parent education. In addition, screening for lateonset conditions should be offered after the newborn period to ensure that parents do not confuse optional testing with routine NBS [46].

\section{Informed Consent for Newborn Screening}

Participants indicated acceptance of mandatory NBS for disorders presenting in infancy, including those without effective treatments, provided that NBS education occurs prenatally. This confirms previous findings that parents are more concerned about NBS education than consent $[17,18,20,47]$ but challenges professionals who believe mandatory NBS is only justified for disorders that fulfill Wilson and Junger's screening principles [6-8].

Mothers expressed several fears related to informed consent for NBS, including the possibility that it might reduce uptake and decrease equal access. Uncertainty does exist about the implementation of informed consent [19], and maintaining a successful informed consent system requires both time and money [48]. In a California pilot study of informed consent and expanded NBS, consent was obtained for only $47 \%$ of births compared to the over $90 \%$ participation rate obtained for traditional mandatory NBS [9]. This significant decrease was attributed to poor hospital consent procedures and demonstrates the difficulties of administering an informed consent system.

The effectiveness of informed consent also depends on the education level, income and English-speaking ability of the patient [49]. Indeed, Spanish-speaking participants were especially concerned that the language barrier 
would contribute to a decrease in participation if NBS was voluntary. For these reasons, mothers supported mandatory NBS for conditions presenting in infancy.

However, mothers did not support mandatory NBS for disorders that present during childhood or adulthood. Due to the divisive nature of this issue, participants believed that if predictive testing is offered, it should be done with informed consent and should not be included in routine NBS.

\section{Limitations}

Our focus groups were limited in number and scope. Although efforts were made to ensure diversity, the groups only included mothers of healthy children and did not represent the U.S. population. In addition, most participants were highly educated; mothers with less education may have had different opinions. Finally, the amount of time allotted to the discussion of such complex issues as NBS for disorders without treatment was limited. Certain subjects, such as NBS for late-onset disorders, should be explored more thoroughly, perhaps as a single topic of future focus groups.

\section{Conclusions}

The study revealed interesting consensuses among participants on issues that cause dissent among public health and healthcare professionals. Parent attitudes differed from some in the medical community with regard to informed consent for NBS, NBS for conditions without effective treatments and predictive testing of children for late-onset disorders. This study provides some insight into how mothers perceive several current and potential issues surrounding the expansion of NBS using new technologies and underscores the need for continued research, involvement and consideration of parent attitudes in the development of NBS policies.

\section{Acknowledgements}

This work was supported by a grant from the Health Resources and Services Administration, Maternal and Child Health Bureau, MCH Project \#1 H46 MC 00189-03. The authors thank Thalia Wood in the Alaska NBS Program for helping with Alaska focus group activities. They also thank all of the mothers who participated in the groups.

\section{References}

1 Wilson JM, Junger G: Principles and practice of screening for disease. Public Health $\mathrm{Pa}$ pers, World Health Organization, Geneva, 1968.

2 Tarini B: The current revolution in newborn screening: new technology, old controversies. Arch Pediatr Adolesc Med 2007;161: 767-772.

-3 Pandor A, Eastham J, Beverley C, Chilcott J, Paisley S: Clinical effectiveness and cost-effectiveness of neonatal screening for inborn errors of metabolism using tandem mass spectrometry: a systematic review. Health Technol Assess 2004;8:1-121.

4 Alexander D, van Dyck PC: A vision of the future of newborn screening. Pediatrics 2006;117:S350-S354

5 Therrell B, Johnson A, Williams D: Status of newborn screening programs in the United States. Pediatrics 2006;117:S212-S252.

6 Kerruish NJ, Webster D, Dickson N: Information and consent for newborn screening: practices and attitudes of service providers. J Med Ethics 2008;34:648-652.

7 Huang MC, Lin SJ: Newborn screening: should explicit parental consent be required? Acta Paediatr Taiwan 2003;44:126-129.

8 The President's Council on Bioethics. The changing moral focus of newborn screening: an ethical analysis by the President's Council on Bioethics, http://bioethics.georgetown. edu/pcbe/reports/newborn_screening/ (accessed June 4, 2009).

9 Feuchtbaum L, Cunningham G, Sciortino $S$ : Questioning the need for informed consent: a case study of California's experience with a pilot newborn screening research project. J Empir Res Hum Res Ethics 2007; 2:3-14.

10 Green NS, Pass KA: Neonatal screening by DNA microarray: spots and chips. Nat Rev Genet 2005;6:147-151.

11 Clarke A: The genetic testing of children. Working Party of the Clinical Genetics Society (UK). J Med Genet 1994;31:785-797.

12 ASHG/ACMG Report: Points to consider: ethical, legal, and psychosocial implications of genetic testing in children and adolescents. Am J Hum Genet 1995;57:1233-1241.

13 National Society of Genetic Counselors: Prenatal and Childhood testing for adult-onset disorders, http://www.nsgc.org (accessed May 27, 2009).

14 Nelson RM, Botkin JR, Kodish ED, Levetown M, Truman JT, Wilfond BS, Harrison CE, Kazura A, Krug E 3rd, Schwartz PA, Donovan GK, Fallat M, Porter IH, Steinberg D; Committee on Bioethics: Ethical issues with genetic testing in pediatrics. Pediatrics 2001;107:1451-1455.
15 Human Genetics Society of Australia: Presymptomatic and predictive testing in children and young people, http://www.hgsa. com.au (accessed May 27, 2009).

16 European Society of Human Genetics: Genetic testing in asymptomatic minors: recommendations of the European Society of Human Genetics. Eur J Hum Genet 2009; 17 : 720-721.

17 Campbell E, Ross LF: Parental attitudes and beliefs regarding the genetic testing of children. Community Genet 2005;8:94-102.

18 Campbell E, Ross LF: Parental attitudes regarding newborn screening of PKU and DMD. Am J Med Genet A 2003;120A:209214.

19 Hargreaves KM, Stweart RJ, Oliver SR: Informed choice and public health screening for children: the case of blood spot screening. Health Expect 2005;8:161-171.

20 Detmar S, Hosli E, Dijkstra N, Nijsingh N, Rijinders M, Verweij M: Information and informed consent for neonatal screening: opinions and preferences of parents. Birth 2007;34:238-244.

21 Detmar S, Dijkstra N, Nijsingh N, Rijnders M, Verweij M, Hosli E: Parental opinions about the expansion of the neonatal screening programme. Community Genet 2008; 11 : $11-17$. 
22 Krueger RA, Casey MA: Focus Groups: A Practical Guide for Applied Research, ed 3. Thousand Oaks, Sage Publications, Inc., 2000, pp 132-137.

-23 Davis TC, Humiston SG, Arnold CL, Bocchini JA, Bass PF 3rd, Kennen EM, Bocchini A, Williams D, Kyler P, Lloyd-Puryear M: Recommendations for effective newborn screening communication: results of focus groups with parents, providers, and experts. Pediatrics 2006;117:S326-S340.

-24 American Academy of Pediatrics Newborn Screening Task Force: Serving the family from birth to the medical home: newborn screening: a blueprint for the future: a call for a national agenda on state newborn screening programs. Pediatrics 2000;106:S389S427.

25 Larsson A, Therrell BR: Newborn screening: the role of the obstetrician. Clin Obstet Gynecol 2002;45:697-710.

-26 American College of Obstetricians and Gynecologists (ACOG): ACOG committee opinion. Number 287, October 2003: newborn screening. Obstet Gynecol 2003;102: 887-889.

-27 Faulkner LA, Feuchtbaum LB, Graham S, Bolstad JP, Cunningham GC: The newborn screening educational gap: what prenatal care providers do compared with what is expected. Am J Obstet Gynecol 2006;194:131137.

$\checkmark 28$ Hasegawa LE, Au SM, Matsumoto CA: The obstetrician's role in newborn metabolic screening: a physician survey. Hawaii Med J 2005;64:239-243.

29 Diem K: Newborn screening - should it be part of prenatal care? Am J Obstet Gynecol 2004;190:874.
30 Kim S, Lloyd-Puryear MA, Tonniges TF: Examination of the communication practices between state newborn screening programs and the medical home. Pediatrics 2003; 111:E120-E126.

31 Lloyd-Puryear MA, Tonniges T, van Dyck, PC, Mann MY, Brin A, Johnson K, McPherson M: American Academy of Pediatrics Newborn Screening Task Force recommendations: how far have we come? Pediatrics 2006;117:S194-S211.

32 Baily MA, Murray TH: Ethics, evidence, and cost in newborn screening. Hastings Cent Rep 2008;38:23-31.

33 Moyer VA, Calonge N, Teutsch SM, Botkin JR; United States Preventative Services Task Force: Expanding newborn screening: process, policy, and priorities. Hastings Cent Rep 2008;38:32-39.

34 Botkin JR, Wright Clayton E, Fost NC, Burke W, Murray TH, Baily MA, Wilfond B, Berg A, Ross LF: Newborn screening technology: proceed with caution. Pediatrics 2006;117: 1793-1799.

35 Bailey DB Jr, Skinner D, Warren SF: Newborn screening for developmental disabilities: reframing presumptive benefit. Am J Public Health 2005;95:1889-1893.

36 Bailey DB Jr: The blurred distinction between treatable and untreatable conditions in newborn screening. Health Matrix Clevel 2009;19:141-153.

37 Wilcken B, Travert G: Neonatal screening for cystic fibrosis: present and future. Acta Paediatr Suppl 1999;88:33-35.

38 Young BB: The Hawaiians; in McDermott JF, Tseng WS, Maretzki TW (eds): People and Cultures of Hawaii: A Psychocutural Profile. Honolulu, The University Press of Hawaii, 1980, pp 5-25.

-39 Braun KL, Mokuau N, Tsark JU: Cultural themes in health, illness, and rehabilitation among Native Hawaiians. Top Geriatr Rehabil 1997;12:19-37.
40 Braun KL, Mokuau N, Hunt GH, Kaanoi M, Gotay CC: Supports and obstacles to cancer survival for Hawaii's native people. Cancer Pract 2002;10:192-200.

$\checkmark 41$ Wertz D, Fanos J, Reilly P: Genetic testing for children and adolescents: who decides? JAMA 1994;272:875-881.

42 Malpas PJ: Predictive genetic testing of children for adult-onset diseases and psychological harm. J Med Ethics 2008;34:275-278.

43 Pelias MK: Genetic testing of children for adult-onset conditions: is testing in the child's best interests? Mt Sinai J Med 2006; 73:605-608.

44 Rhodes R: Why test children for adult-onset genetic diseases? Mt Sinai J Med 2006;73: 609-616.

45 Duncan RE, Savulescu J, Gillam L, Williamson R, Delatycki MB: An international survey of predictive genetic testing in children for adult onset conditions. Genet Med 2005; 7:390-396.

46 Ross L: Screening for conditions that do not meet the Wilson and Junger criteria: the case of Duchenne muscular dystrophy. Am J Med Genet A 2006;140:914-922.

47 Faden R, Chwalow J, Holtzmann NA, Horn SD: A survey to evaluate parental consent as public policy for neonatal screening. Am J Public Health 1982;72:1350.

-48 Raffle AE: Information about screening - is it to achieve high uptake or to ensure informed choice? Health Expect 2001;4:92-98.

49 Mortensen MG, Kiyak HA, Omnell L: Patient and parent understanding of informed consent in orthodontics. Am J Orthod Dentofacial Orthop 2003;124:541-550. 